\title{
Bacteriological Characteristics of Staphylococcus aureus Isolates from Humans and Bulk Milk
}

\author{
E. Hata, ${ }^{* 1}$ K. Katsuda,† H. Kobayashi,‡ K. Nishimori,‡ I. Uchida, ${ }^{\star}$ M. Higashide,§ E. Ishikawa,§ \\ T. Sasaki,§ and M. Eguchi* \\ *Hokkaido Research Station, National Institute of Animal Health, 4 Hitsujigaoka, Toyohira-Ku, Sapporo, Hokkaido 062-0045, Japan \\ †Shichinohe Research Unit, National Institute of Animal Health, 31 Uminai, Shichinohe, Kamikita, Aomori 039-2586, Japan \\ $\ddagger$ National Institute of Animal Health, 3-1-5 Kannondai, Tsukuba, Ibaraki 305-0856, Japan \\ §Kotobiken Medical Laboratories Inc., 445-1 Kamiyokoba, Tsukuba, Ibaraki 305-0854, Japan
}

\begin{abstract}
The aim of this study was to clarify the epidemiological association and bacteriological characteristics of human and animal Staphylococcus aureus isolates. Pulsed-field gel electrophoresis showed that pulsotypes (PT) of isolates from bulk milk differed from PT from human isolates, suggesting that there is no epidemiological association between isolates from these 2 sources. The absence of a common PT could result from the lack of contact between the sources. Methicillinresistant $S$. aureus from human secretions and $S$. aureus from bulk milk in Japan consisted of 1 and 2 dominant clusters, respectively, whereas methicillinsusceptible $S$. aureus from humans consisted of assorted clusters. Isolates belonging to the dominant clusters showed the coagulase serotype, the capsule serotype, detection of exotoxin genes, and antimicrobial susceptibility. Isolates from bulk milk did not show the penicillin-binding protein $2 \mathrm{a}$ gene, and 252 of 275 isolates belonging to the 2 dominant clusters of bulk milk were susceptible to ampicillin, cefazolin, erythromycin, chloramphenicol, oxacillin, and vancomycin. Moreover, the LukM/LukF'-PV leukotoxin gene was detected in 233 of 275 isolates belonging to the dominant clusters in bulk milk isolates. These results support the hypothesis that a number of factors play a role in the adaptation of $S$. aureus isolates to specific hosts.
\end{abstract}

Key words: Staphylococcus aureus, pulsed-field gel electrophoresis, LukM/LukF'-PV

\section{INTRODUCTION}

Staphylococcus aureus has attracted attention as a contagious causal bacterium of bovine mastitis that can cause enormous economic losses to dairy farmers. More-

Received June 18, 2007.

Accepted October 30, 2007.

${ }^{1}$ Corresponding author: ehata@affrc.go.jp over, $S$. aureus is an important causal bacterium of a variety of human diseases such as impetigo, abscesses, endocarditis, toxic shock syndrome, foodborne diseases, and staphylococcal scalded skin syndrome (Ladhani et al., 1999; Dinges et al., 2000). Staphylococcus aureus is an important causal bacterium for both human and animal diseases; therefore, clarification of the relationship between human isolates and bovine milk isolates of $S$. aureus is important for both public and animal hygiene.

Staphylococcus aureus is present in a variety of locations on the dairy farm, and several studies suggest that transfer of $S$. aureus between humans and cows is possible (Matos et al., 1991; Roberson et al., 1994; Zadoks et al., 2000). These studies focused primarily on the role of humans as a source of $S$. aureus IMI for dairy cattle. Multidrug-resistant staphylococcal isolates such as methicillin-resistant $S$. aureus (MRSA) were isolated primarily from human samples, but such isolates were detected in animal samples (Lee et al., 2004). Additionally, a large-scale outbreak of S. aureus foodborne disease due to low-fat milk occurred in Japan in 2000 (Asao et al., 2003). Thus, the transfer of $S$. aureus between humans and cows may result in serious problems.

Bacterial genotyping is a common approach to examining bacterial origins and relationships. Numerous bacterial genotyping methods have been developed. Of these, pulsed-field gel electrophoresis (PFGE) is a DNA-based typing technique that has greater typeability, within-laboratory reproducibility, and discriminatory power than other typing methods such as phage typing and binary typing (Bannerman et al., 1995; Zadoks et al., 2002). In the past, PFGE was regarded as the gold standard for the typing of $S$. aureus (Bannerman et al., 1995).

Many of the exotoxins, extracellular enzymes, surface proteins, and capsule polysaccharides produced by $S$. aureus were involved in the above-mentioned diseases. For example, exfoliative toxins are a virulence factor 
for staphylococcal scalded skin syndrome, and staphylococcal enterotoxins are recognized causes of foodborne disease and bovine mastitis (Dinges et al., 2000; Kuroishi et al., 2003; Komine et al., 2004). Therefore, profiling of various bacterial factors can provide important information for estimating the pathogenicity of bacterial strains.

In the present study, PFGE analysis was conducted to assess coagulase and capsule serotyping; to detect exotoxin genes such as staphylococcal enterotoxins, staphylococcal enterotoxin-like toxins, toxic shock syndrome toxin, exfoliative toxins, epidermal cell differentiation inhibitor (EDIN), hemolysin (HL), and leukocidin (Luk); and to evaluate antimicrobial susceptibility between $S$. aureus isolates from humans and bovine milk.

\section{MATERIALS AND METHODS}

A total of 393 S. aureus isolates were tested. They included 66 MRSA isolates and 48 methicillin-sensitive S. aureus (MSSA) isolates from humans, and 279 isolates from bulk bovine milk. Human samples such as vaginal discharge $(\mathrm{n}=8)$, throat swabs $(\mathrm{n}=8)$, pus $(\mathrm{n}=$ $8)$, eye mucus $(n=8)$, phlegm $(n=8)$, decubital ulcer samples $(n=8)$, aural discharge $(n=8)$, nasal discharge $(\mathrm{n}=12)$, urine $(\mathrm{n}=8)$, skin $(\mathrm{n}=8)$, amygdalo $(\mathrm{n}=$ $4)$, synovial fluid $(\mathrm{n}=5)$, peritoneal exudate $(\mathrm{n}=9)$, alimentary tract smear $(\mathrm{n}=4)$, and wound samples $(n=8)$ were collected from 114 patients in 81 hospitals located in 5 prefectures in Japan (Chiba, Gunma, Ibaraki, Tochigi, and Tokyo) between April and July 2004. Bulk milk samples were collected from 279 dairy farms located in 10 districts of Hokkaido, Japan (Abashiri, $\mathrm{n}=31$; Hiyama, $\mathrm{n}=15$; Ishikari, $\mathrm{n}=31$; Kamikawa, $\mathrm{n}=31$; Kushiro, $\mathrm{n}=31$; Nemuro, $\mathrm{n}=31$; Oshima, $\mathrm{n}=$ 16; Rumoi, $\mathrm{n}=31$; Soya, $\mathrm{n}=31$; and Tokachi, $\mathrm{n}=$ 31 ) in July 2001. One isolate was tested per sample. Bacterial isolates were stored in trypticase soy broth (Eiken Chemical Co., Tokyo, Japan) containing 25\% glycerol and maintained at $-80^{\circ} \mathrm{C}$. All $S$. aureus isolates were confirmed as gram-positive, catalase-positive, oxidase-negative, or tube coagulase test-positive cocci with rabbit plasma (Eiken Chemical Co.) and gave positive results on Voges-Proskauer tests (Eiken Chemical Co.). The results were reconfirmed by PCR amplification of the species-specific 442-bp fragment or DNA homology (Martineau et al., 1998; Hata et al., 2006).

Genomic DNA for PFGE was prepared following the procedure reported by Hata et al. (2006). Thinly sliced plugs were digested with restriction endonuclease Sma I (Toyobo, Osaka, Japan). The conditions for electrophoresis (Hata et al., 2006) and analysis (Mørk et al., 2005) were established based on the reported procedures. A pulsotype (PT) was defined as a unique electrophoretic banding pattern defined by a combination of computeraided and visual interpretations. Banding patterns were compared according to criteria defined by Tenover et al. (1995). A dendrogram was created with an optimization and position tolerance setting of $1 \%$ from each PT; PT that showed more than $80 \%$ similarity in this dendrogram were defined as the same cluster (Mørk et al., 2005).

The PCR detection for pyrogenic toxin superantigen (PTSAg) genes (sea, seb, sec, sed, see, seg, seh, sei, selj, selk, sell, selm, seln, selo, selp, selq, selr, and tst) was performed following the procedure reported by Omoe et al. (2005). The fem $\mathrm{A}$ and $f e m \mathrm{~B}$ genes, which are specific to $S$. aureus, were used as internal positive controls. The detection of ET (ETA and ETB), Luks [Panton-Valentine leukocidin components $\mathrm{S}$ and $\mathrm{F}$ (LukF'$\mathrm{PV}$ and LukS'-PV), LukM and LukF'-PV, LukE and LukD], HL (HLA, HLB, HLD, and HLG), and EDIN genes (eta, etb, PVL, lukM/lukF'-PV, lukE/lukD, hla, $h l b, h l d, h l g$, and edin) by PCR was performed according to the procedure reported by Jarraud et al. (2002).

Coagulase was serotyped using a commercial coagulase typing kit (Denka Seiken, Tokyo, Japan). Capsules were serotyped using rabbit antisera against $S$. aureus capsule serotypes $1,2,5$, and 8 following the procedure reported by Lee et al. (1990).

The minimum inhibitory concentrations of $S$. aureus isolates were determined according to the National Committee for Clinical Laboratory Standards (NCCLS) method for the agar dilution antimicrobial susceptibility test procedure for bacteria that grow aerobically M7A5 (NCCLS, 2000). The tested antibiotics were ampicillin, cefazolin, erythromycin, chloramphenicol, oxacillin, and vancomycin. Except in the cases of oxacillin and vancomycin, the test is performed by inoculating $S$. aureus isolates onto Mueller-Hinton agar (Difco, Sparks, MD) supplemented with diluted antibiotics. Muller-Hinton agar supplemented with $4 \%$ (wt/vol) $\mathrm{NaCl}$ was used for oxacillin tests, and brain-heart infusion agar (Difco) was used for the vancomycin tests. The breakpoints for each antimicrobe were based on NCCLS Guide M31-A (NCCLS, 2002). Reference strain $S$. aureus ATCC29213 served as the assay control. The presence of penicillin-binding protein 2a gene (mecA) was tested by PCR according as previously described by Jonas et al. (2002).

\section{RESULTS}

Pulsed-field gel electrophoresis identified $172 \mathrm{PT}$ in 23 clusters (A to $\mathrm{W}$ ) in the tested isolates. Of the 23 clusters, $\mathrm{J}$ was the dominant cluster of human MRSA isolates $(72.7 \%)$, and $\mathrm{O}(35.1 \%)$ and $\mathrm{V}(59.1 \%)$ were the 
HATA ET AL.

Table 1. Results of pulsed-field gel electrophoresis (PFGE) analysis: coagulase and capsule serotypes in Staphylococcus aureus isolates from humans and bulk milk

\begin{tabular}{|c|c|c|c|c|c|c|}
\hline \multirow{2}{*}{$\begin{array}{l}\text { PFGE } \\
\text { cluster }\end{array}$} & \multirow[b]{2}{*}{$\mathrm{PT}$} & \multirow{2}{*}{$\underset{(\%)}{\operatorname{MRSA}^{1}}$} & \multirow{2}{*}{$\begin{array}{c}\operatorname{MSSA}^{1} \\
(\%)\end{array}$} & \multirow{2}{*}{$\begin{array}{c}\text { Bulk } \\
\text { milk }(\%)\end{array}$} & \multicolumn{2}{|l|}{ Serotype $^{2}$} \\
\hline & & & & & Coagulase (n) & Capsule (n) \\
\hline A & $3^{3}$ & & $3^{4}(6.3)$ & & $\mathrm{V}(3)$ & $8(3)$ \\
\hline B & 1 & & $1(2.1)$ & & $\mathrm{V}(1)$ & $8(1)$ \\
\hline $\mathrm{C}$ & 1 & & & $1^{4}(0.4)$ & $\mathrm{V}(1)$ & $5(1)$ \\
\hline $\mathrm{D}$ & 4 & $6^{4}(9.1)$ & & & I (6) & $8(6)$ \\
\hline $\mathrm{E}$ & 2 & $2(3.0)$ & & & I (2) & $8(2)$ \\
\hline $\mathrm{F}$ & 1 & & & $1(0.4)$ & VI (1) & $8(1)$ \\
\hline G & 1 & & & $1(0.4)$ & II (1) & $5(1)$ \\
\hline $\mathrm{H}$ & 5 & $1(1.5)$ & & $4(1.4)$ & II (1), III (2), V (1), VI (1) & $1(1), 5(4)$ \\
\hline I & 2 & & $1(2.1)$ & $1(0.4)$ & II (2) & $5(1), \mathrm{NT}^{5}(1)$ \\
\hline $\mathrm{J}$ & 39 & $48(72.7)$ & $2(4.2)$ & $1(0.4)$ & II (51) & $5(49), \mathrm{NT}(2)$ \\
\hline $\mathrm{K}$ & 3 & $2(3.0)$ & $1(2.1)$ & & II (2), VIII (1) & $5(3)$ \\
\hline $\mathrm{L}$ & 5 & & $4(8.3)$ & $1(0.4)$ & II (1), VIII (4) & $5(2), 8(3)$ \\
\hline M & 8 & $2(3.0)$ & $4(8.3)$ & $2(0.7)$ & III (5), VII (3) & 5 (4), 8 (3), NT (1) \\
\hline $\mathrm{N}$ & 4 & $2(3.0)$ & $1(2.1)$ & $2(0.7)$ & II (2), VI (2), NT (1) & $5(4), 8(1)$ \\
\hline $\mathrm{O}$ & 32 & $1(1.5)$ & $11(22.9)$ & $98(35.1)$ & III (3), V (1), VI (93), VII (13) & 5 (98), 8 (8), NT (4) \\
\hline $\mathrm{P}$ & 1 & & $1(2.1)$ & & VII (1) & NT (1) \\
\hline Q & 5 & & $5(10.4)$ & $1(0.4)$ & VII (6) & $8(6)$ \\
\hline $\mathrm{R}$ & 1 & $2(3.0)$ & & & III (2) & $5(2)$ \\
\hline $\mathrm{S}$ & 10 & & $10(20.8)$ & & II (1), III (6), VII (3) & $8(10)$ \\
\hline $\mathrm{T}$ & 2 & & $2(4.2)$ & & VII (2) & NT (2) \\
\hline $\mathrm{U}$ & 2 & & $2(4.2)$ & & VI (2) & $8(2)$ \\
\hline $\mathrm{V}$ & 39 & & & $165(59.1)$ & III (1), VI (164) & $8(165)$ \\
\hline $\mathrm{W}$ & 1 & & & $1(0.4)$ & I (1) & $8(1)$ \\
\hline
\end{tabular}

\footnotetext{
${ }^{1}$ Methicillin-resistant (MRSA) and methicillin-sensitive (MSSA) S. aureas isolates are from human samples.

${ }^{2}$ Coagulase serotypes are shown in Roman numerals, and capsule serotypes are shown in Arabic numerals.

${ }^{3}$ Number of pulsotypes (PT).

${ }^{4}$ Number of isolates.

${ }^{5} \mathrm{NT}=$ nontypeable.
}

dominant clusters of bulk milk isolates. On the other hand, human MSSA isolates showed no obviously dominant clusters (Table 1).

The clusters J, M, N, and $\mathrm{O}$ were common clusters among human MRSA, human MSSA, and bulk milk isolates. The cluster $\mathrm{K}$ was the common cluster between human MRSA and MSSA. The cluster $\mathrm{H}$ was the common cluster between human MRSA and bulk milk isolates. Moreover, I, L, and Q were common clusters between human MSSA and bulk milk isolates (Table 1). Yet, common PT was not confirmed among human MRSA, human MSSA, and bulk milk isolates.

The analytical results of PFGE were linked to phenotypes such as the coagulase and capsule serotypes. Of the 51 isolates belonging to $\mathrm{J}$, the dominant cluster of human MRSA, were all coagulase serotype II, and human MRSA isolates were capsule serotype 5 . Of the 165 isolates belonging to $\mathrm{V}$, a dominant cluster of bulk milk isolates, 164 were coagulase serotype VI, and all were capsule serotype 8 . Moreover, of the 110 isolates belonging to $\mathrm{O}$, a dominant cluster of bulk milk isolates, 92 isolates from bulk milk were coagulase serotype VI and capsule serotype 5 (Table 1 ).
Certain PT belonging to $\mathrm{O}$ and $\mathrm{V}$ were found frequently and in many isolates. The most common PT of $\mathrm{V}$ was found in 32 isolates, and the most common PT of $\mathrm{O}$ was found in 57 isolates. In contrast, few frequent PT were found among human isolates.

The analytical results of PFGE were linked to the presence of exotoxin genes as well as to the coagulase and capsule serotypes. In the 51 isolates belonging to J, sec, seg, sei, sell, selm, selo, tst, lukE/lukD, hla, hld, and $h l g$ were often detected in $36(70.6 \%), 50(98.0 \%)$, 50 (98.0\%), 36 (70.6\%), 50 (98.0\%), $49(96.1 \%), 36$ (70.6\%), $51(100 \%), 51(100 \%), 51(100 \%)$, and 51 (100\%), respectively (Table 2 ). In the 165 isolates belonging to V, sec, seg, sei, sell, tst, lukE/lukD, lukM/ $l u k F^{\prime}-P V, h l a, h l b, h l d$, and $h l g$ were often detected in 138 (83.6\%), 164 (99.4\%), 164 (99.4\%), 137 (83.0\%), 138 (83.6\%), 157 (95.2\%), 156 (94.5\%), $157(95.2 \%), 165$ (100\%), 165 (100\%), and $162(98.2 \%)$, respectively (Table 2). In the 110 isolates belonging to $\mathrm{O}$, lukE/lukD, $l u k M / l u k F^{\prime}-P V, h l a, h l b, h l d$, and hlg were often detected in 105 (95.5\%), 79 (71.8\%), $102(92.7 \%), 92$ (83.6\%), $109(99.1 \%)$, and $102(92.7 \%)$, respectively, however, 90 (81.8\%) showed no PTSAg genes, unlike in clusters $\mathrm{J}$ and $\mathrm{V}$ (Table 2). 
Table 2. Toxin gene detection in each cluster of Staphylococcus aureus isolates by pulsed-field gel electrophoresis

\begin{tabular}{|c|c|c|c|c|c|c|c|c|}
\hline \multirow[b]{3}{*}{ Toxin genes } & \multicolumn{8}{|c|}{ Cluster } \\
\hline & \multicolumn{2}{|c|}{$\mathrm{J}(\mathrm{n}=51)$} & \multicolumn{2}{|c|}{$\mathrm{O}(\mathrm{n}=110)$} & \multicolumn{2}{|c|}{$\mathrm{V}(\mathrm{n}=165)$} & \multicolumn{2}{|c|}{ Others $(\mathrm{n}=67)$} \\
\hline & $\mathrm{n}$ & $\%$ & $\mathrm{n}$ & $\%$ & $\mathrm{n}$ & $\%$ & $\mathrm{n}$ & $\%$ \\
\hline sea & 2 & 3.9 & 3 & 2.7 & 0 & 0 & 5 & 7.5 \\
\hline seb & 13 & 25.5 & 3 & 2.7 & 0 & 0 & 8 & 11.9 \\
\hline $\mathrm{sec}$ & 36 & 70.6 & 2 & 1.8 & 138 & 83.6 & 12 & 17.9 \\
\hline sed & 0 & 0 & 1 & 0.9 & 1 & 0.6 & 1 & 1.5 \\
\hline see & 0 & 0 & 0 & 0 & 0 & 0 & 0 & 0 \\
\hline seg & 50 & 98.0 & 8 & 7.3 & 164 & 99.4 & 44 & 65.7 \\
\hline seh & 0 & 0 & 9 & 8.2 & 0 & 0 & 2 & 3.0 \\
\hline sei & 50 & 98.0 & 5 & 4.5 & 164 & 99.4 & 44 & 65.7 \\
\hline selj & 0 & 0 & 1 & 0.9 & 0 & 0 & 3 & 4.5 \\
\hline selk & 3 & 5.9 & 3 & 2.7 & 0 & 0 & 3 & 4.5 \\
\hline sell & 36 & 70.6 & 1 & 0.9 & 137 & 83.0 & 13 & 19.4 \\
\hline selm & 50 & 98.0 & 3 & 2.7 & 0 & 0 & 28 & 41.8 \\
\hline seln & 22 & 43.1 & 0 & 0 & 79 & 47.9 & 15 & 22.4 \\
\hline selo & 49 & 96.1 & 2 & 1.8 & 0 & 0 & 25 & 37.3 \\
\hline selp & 11 & 21.6 & 4 & 3.6 & 0 & 0 & 7 & 10.4 \\
\hline selq & 2 & 3.9 & 4 & 3.6 & 0 & 0 & 2 & 3.0 \\
\hline selr & 0 & 0 & 1 & 0.9 & 0 & 0 & 3 & 4.5 \\
\hline$t s t$ & 36 & 70.6 & 6 & 5.5 & 138 & 83.6 & 31 & 46.3 \\
\hline$s e, s e l$, and $t s t$ negative & 0 & 0 & 90 & 81.8 & 1 & 0.6 & 6 & 9.0 \\
\hline eta & 0 & 0 & 0 & 0 & 0 & 0 & 0 & 0 \\
\hline$e t b$ & 0 & 0 & 0 & 0 & 0 & 0 & 3 & 4.5 \\
\hline$P V L$ & 0 & 0 & 0 & 0 & 0 & 0 & 1 & 1.5 \\
\hline$l u k E / l u k D$ & 51 & 100 & 105 & 95.5 & 157 & 95.2 & 46 & 68.7 \\
\hline$l u k M / l u k F^{\prime}-P V$ & 0 & 0 & 79 & 71.8 & 156 & 94.5 & 0 & 0 \\
\hline hla & 51 & 100 & 102 & 92.7 & 157 & 95.2 & 66 & 98.5 \\
\hline$h l b$ & 4 & 7.8 & 92 & 83.6 & 165 & 100 & 27 & 40.3 \\
\hline hld & 51 & 100 & 109 & 99.1 & 165 & 100 & 67 & 100 \\
\hline hlg & 51 & 100 & 102 & 92.7 & 162 & 98.2 & 62 & 92.5 \\
\hline edin & 0 & 0 & 1 & 0.9 & 0 & 0 & 0 & 0 \\
\hline
\end{tabular}

The gene of staphylococcal enterotoxin A (SEA), the main pathogen of staphylococcal foodborne disease (Oda, 1998; Dinges et al., 2000; Asao et al., 2003), was hardly detected, and sea was detected in only 10 of all isolates (2.5\%; Table 2). Moreover, lukM/lukF'-PV was frequently detected only in isolates belonging to $\mathrm{O}$ and $\mathrm{V}$, in dominant clusters of bulk milk isolates (Table 2).

None of the isolates from bulk milk showed the presence of mecA. Of the 165 isolates belonging to $\mathrm{V}$ and the 98 isolates from bulk milk belonging to $\mathrm{O}, 2(1.2 \%)$ and $11(11.2 \%)$, respectively, were resistant to ampicillin. Moreover, these isolates were susceptible to other antimicrobial agents (Table 3). Of the 51 isolates belonging to $\mathrm{J}$, the number of isolates showing resistance to ampicillin, cefazolin, erythromycin, chloramphenicol, oxacillin, and vancomycin were $50(98.0 \%), 48$ (94.1\%), 47 (92.2\%), 6 (11.8\%), $48(94.1 \%)$, and $0(0 \%)$, respectively (Table 3 ).

\section{DISCUSSION}

Staphylococcus aureus is a causal bacterium of various human and animal diseases, but the correlation between $S$. aureus spreading as a human pathogen and as an animal pathogen has not been adequately clarified. An extensive outbreak of staphylococcal foodborne disease caused by the ingestion of low-fat milk occurred in June and July 2000 in Japan (Asao et al., 2003). This outbreak was the impetus that led people to examine the relationship between these human and animal pathogens. When the outbreak occurred, S. aureus in dairy cows was suspected as the causal bacterium. The SEA was detected as the pathogenic factor of this outbreak, but the origin of $S$. aureus producing SEA was not fully elucidated (Asao et al., 2003). In the present study, sea was not detected in most $S$. aureus samples from humans, bovine mastitic milk, or bulk milk (Hata et al., 2006). Thus, S. aureus in bovine milk may have a low possibility of involvement in staphylococcal foodborne disease.

Multidrug-resistant staphylococci have long been suspected as the causal bacterium of nosocomial infection (Livermore, 2000; Aires de Sousa and de Lencastre, 2004); MRSA and methicillin-resistant coagulase-negative staphylococci (MRCNS) have been isolated from domestic animals (Lee et al., 2004). The present study found no mecA in $S$. aureus isolates from bulk milk, and most isolates were susceptible to all of the tested 
Table 3. The relationships between clusters as determined by pulsed-field gel electrophoresis and frequency of resistance in Staphylococcus aureus isolates from humans and bulk milk

\begin{tabular}{|c|c|c|c|c|c|c|c|c|c|}
\hline \multirow{3}{*}{$\begin{array}{l}\text { Antimicrobial agent } \\
(\mathrm{n}=67)\end{array}$} & \multirow{3}{*}{$\begin{array}{c}\text { Breakpoint } \\
(\mu \mathrm{g} / \mathrm{mL})\end{array}$} & \multicolumn{8}{|c|}{ Cluster } \\
\hline & & \multicolumn{2}{|c|}{$\mathrm{J}(\mathrm{n}=51)$} & \multicolumn{2}{|c|}{$\mathrm{O}(\mathrm{n}=110)$} & \multicolumn{2}{|c|}{$\mathrm{V}(\mathrm{n}=165)$} & \multicolumn{2}{|c|}{ Others } \\
\hline & & $\mathrm{n}$ & $\%$ & $\mathrm{n}$ & $\%$ & $\mathrm{n}$ & $\%$ & $\mathrm{n}$ & $\%$ \\
\hline Ampicillin & $\leq 0.5$ & 50 & 98.0 & 20 & 18.2 & 2 & 1.2 & 53 & 79. \\
\hline Cefazolin & $\leq 32$ & 48 & 94.1 & 1 & 0.9 & 0 & 0 & 16 & 23. \\
\hline Erythromycin & $\leq 8$ & 47 & 92.2 & 0 & 0 & 0 & 0 & 20 & 29. \\
\hline Chloramphenicol & $\leq 32$ & 6 & 11.8 & 0 & 0 & 0 & 0 & 1 & 1. \\
\hline Oxacillin & $\leq 4$ & 48 & 94.1 & 1 & 0.9 & 0 & 0 & 17 & 25. \\
\hline Vancomycin & $\leq 32$ & 0 & 0 & 0 & 0 & 0 & 0 & 0 & 0 \\
\hline
\end{tabular}

antimicrobial agents. This result supports the reasonable use of antimicrobial agents on Japanese dairy farms. To the best of our knowledge, MRSA and MRCNS have not been isolated from Japanese dairy farms or dairy cows, but the spread of these bacteria among dairy farms could negate the effect of most antibiotics that have been used for therapy of the bovine mastitis. Because the random amplified polymorphic DNA patterns of isolates from animals were identical to the patterns of certain isolates from humans in a study by Lee (2003), we suggest the possibility that humans are a potential source of MRSA and MRCNS spreading among domestic animals. Therefore, it is necessary to pay close attention to direct contact between humans and animals, to milking hygiene, and to the reasonable use of antimicrobial agents to prevent the occurrence of multidrug-resistant bacteria on dairy farms.

In the present study, we found no common PT between human isolates and bulk milk isolates, suggesting that there was no epidemiological association between isolates from humans and those from bulk milk. The absence of a common PT is considered the result of a lack of contact between the 2 sources.

Three dominant clusters were confirmed present by PFGE in human MRSA isolates and bulk milk isolates. All of the isolates belonging to $\mathrm{V}$, the dominant cluster of bulk milk isolates, were isolated from bulk milk, as were most of the isolates belonging to $\mathrm{O}$. In contrast, most of the isolates belonging to $\mathrm{E}$, the dominant cluster of human MRSA isolates, were identified in human MRSA samples. Moreover, the isolates belonging to J, $\mathrm{O}$, and $\mathrm{V}$ showed individual characteristics for the coagulase serotype, the capsule serotype, the presence of exotoxin genes, and antimicrobial susceptibility. We detected $l u k M / l u k F^{\prime}-P V$ only in isolates belonging to $\mathrm{O}$ and $\mathrm{V}$, the predominant clusters of bulk milk isolates. These results suggest the possibility that specific isolates possessing a number of factors adapt to specific hosts and easily carry antimicrobial resistance factors. LukM/LukF'-PV has greater leukotoxic activity against bovine polymorphonuclear cells than other bicomponent toxins (Barrio et al., 2006); thus, LukM/LukF'-PV may contribute to resistance to the attack of bovine polymorphonuclear cells. The clarification of these phenomena may aid in elucidating mechanisms of S. aureus infection and pathogeny against each host.

\section{ACKNOWLEDGMENTS}

We thank Y. Kumano at Hokkaido Dairy Milk Recording \& Testing Association, and J. Nishibu and T. Ichino at Tokachi Nôkyô-ren, for help with the collection of bulk milk. We thank J. C. Lee at the Brigham and Women's Hospital and Harvard University Medical School, who kindly derived $S$. aureus strains for capsular typing. We thank R. Haneda and A. Iijima for their technical assistance. This work was supported by grants from the National Agricultural Research Organization, Japan.

\section{REFERENCES}

Aires de Sousa, M., and H. de Lencastre. 2004. Bridges from hospitals to the laboratory: Genetic portraits of methicillin-resistant Staphylococcus aureus clones. FEMS Immunol. Med. Microbiol. 40:101-111.

Asao, T., Y. Kumeda, T. Kawai, T. Shibata, H. Oda, K. Haruki, H. Nakazawa, and S. Kozaki. 2003. An extensive outbreak of staphylococcal food poisoning due to low-fat milk in Japan: Estimation of enterotoxin A in the incriminated milk and powdered skim milk. Epidemiol. Infect. 130:33-40.

Bannerman, T. L., D. Hancock, F. Tenover, and J. M. Miller. 1995. Pulsedfield gel electrophoresis as a replacement for bacteriophage typing of Staphylococcus aureus. J. Clin. Microbiol. 33:551-555.

Barrio, M. B., P. Rainard, and G. Prevost. 2006. LukM/LukF'-PV is the most active Staphylococcus aureus leukotoxin on bovine neutrophils. Microbes Infect. 8:2068-2074.

Dinges, M. M., P. M. Orwin, and P. M. Schlievert. 2000. Exotoxins of Staphylococcus aureus. Clin. Microbiol. Rev. 13:16-34.

Hata, E., K. Katsuda, H. Kobayashi, T. Ogawa, T. Endô, and M. Eguchi. 2006. Characteristics and epidemiologic genotyping of Staphylococcus aureus isolates from bovine mastitic milk in Hokkaido, Japan. J. Vet. Med. Sci. 68:165-170.

Jarraud, S., C. Mougel, J. Thioulouse, G. Lina, H. Meugnier, F. Forey, X. Nesme, J. Etienne, and F. Vandenesch. 2002. Relationships between Staphylococcus aureus genetic background, virulence factors, agr groups (alleles), and human disease. Infect. Immun. 70:631-641. 
Jonas, D., M. Speck, F. D. Daschner, and H. Grundmann. 2002. Rapid PCR-based identification of methicillin-resistant Staphylococcus aureus from screening swabs. J. Clin. Microbiol. 40:1821-1823.

Komine, K., T. Kuroishi, Y. Komine, K. Watanabe, J. Kobayashi, T. Yamaguchi, S. Kamata, and K. Kumagai. 2004. Induction of nitric oxide production mediated by tumor necrosis factor alpha on staphylococcal enterotoxin C-stimulated bovine mammary gland cells. Clin. Diagn. Lab. Immunol. 11:203-210.

Kuroishi, T., K. Komine, K. Asai, J. Kobayashi, K. Watanabe, T. Yamaguchi, S. Kamata, and K. Kumagai. 2003. Inflammatory responses of bovine polymorphonuclear neutrophils induced by staphylococcal enterotoxin $\mathrm{C}$ via stimulation of mononuclear cells. Clin. Diagn. Lab. Immunol. 10:1011-1018.

Ladhani, S., C. L. Joannou, D. P. Lochrie, R. W. Evans, and S. M. Poston. 1999. Clinical, microbial, and biochemical aspects of the exfoliative toxins causing staphylococcal scalded-skin syndrome. Clin. Microbiol. Rev. 12:224-242.

Lee, J. H. 2003. Methicillin (oxacillin)-resistant Staphylococcus aureus strains isolated from major food animals and their potential transmission to humans. Appl. Environ. Microbiol. 69:6489-6494.

Lee, J. H., J. M. Jeong, Y. H. Park, S. S. Choi, Y. H. Kim, J. S. Chae, J. S. Moon, H. Park, S. Kim, and S. K. Eo. 2004. Evaluation of the methicillin-resistant Staphylococcus aureus (MRSA)-Screen latex agglutination test for detection of MRSA of animal origin. J. Clin. Microbiol. 42:2780-2782.

Lee, J. C., M. J. Liu, J. Parsonnet, and R. D. Arbeit. 1990. Expression of type 8 capsular polysaccharide and production of toxic shock syndrome toxin 1 are associated among vaginal isolates of Staphylococcus aureus. J. Clin. Microbiol. 28:2612-2615.

Livermore, D. M. 2000. Antibiotic resistance in staphylococci. Int. J. Antimicrob. Agents 16(Suppl. 1):3-10.

Martineau, F., F. J. Picard, P. H. Roy, M. Ouellette, and M. G. Bergeron. 1998. Species-specific and ubiquitous-DNA-based assays for rapid identification of Staphylococcus aureus. J. Clin. Microbiol. 36:618-623.

Matos, J. S., D. G. White, R. J. Harmon, and B. E. Langlois. 1991. Isolation of Staphylococcus aureus from sites other than the lactating mammary gland. J. Dairy Sci. 74:1544-1549.
Mørk, T., T. Tollersrud, B. Kvitle, H. J. Jørgensen, and S. Waage. 2005. Comparison of Staphylococcus aureus clusters recovered from cases of bovine, ovine, and caprine mastitis. J. Clin. Microbiol. 43:3979-3984.

National Committee for Clinical Laboratory Standards. 2000. Methods for dilution antimicrobial susceptibility tests for bacteria that grow aerobically; approved standard 5th edition M7-A5. National Committee for Clinical Laboratory Standards, Wayne, PA.

National Committee for Clinical Laboratory Standards. 2002. Performance standerds for antimicrobial disk and dilution susceptibility tests for bacteria isolated from animals; approved standard-2nd edition M31-A. National Committee for Clinical Laboratory Standards, Wayne, PA.

Oda, T. 1998. A review of staphylococcal food poisoning in Japan. J. Food Hyg. Soc. Jap. 39:179-186.

Omoe, K., D. L. Hu, H. Takahashi-Omoe, A. Nakane, and K. Shinagawa. 2005. Comprehensive analysis of classical and newly described staphylococcal superantigenic toxin genes in Staphylococcus aureus isolates. FEMS Microbiol. Lett. 246:191-198.

Roberson, J. R., L. K. Fox, D. D. Hancock, J. M. Gay, and T. E. Besser 1994. Ecology of Staphylococcus aureus isolated from various sites on dairy farms. J. Dairy Sci. 77:3354-3364.

Tenover, F. C., R. D. Arbeit, R. V. Goering, P. A. Mickelsen, B. E. Murray, D. H. Persing, and B. Swaminathan. 1995. Interpreting chromosomal DNA restriction patterns produced by pulsed-field gel electrophoresis: Criteria for bacterial strain typing. J. Clin. Microbiol. 33:2233-2239.

Zadoks, R., W. van Leeuwen, H. Barkema, O. Sampimon, H. Verbrugh, Y. H. Schukken, and A. van Belkum. 2000. Application of pulsed-field gel electrophoresis and binary typing as tools in veterinary clinical microbiology and molecular epidemiologic analysis of bovine and human Staphylococcus aureus isolates. J. Clin. Microbiol. 38:1931-1939.

Zadoks, R. N., W. B. van Leeuwen, D. Kreft, L. K. Fox, H. W. Barkema, Y. H. Schukken, and A. van Belkum. 2002. Comparison of Staphylococcus aureus isolates from bovine and human skin, milking equipment, and bovine milk by phage typing, pulsed-field gel electrophoresis, and binary typing. J. Clin. Microbiol. 40:38943902. 